\title{
CONDUTAS DE RISCO E PUBERDADE
}

\section{Mônica Assunção Costa Lima ${ }^{1}$}

\begin{abstract}
Resumo: O texto discute as condutas de risco praticadas por adolescentes na contemporaneidade e as faz dialogar com o conceito de puberdade em psicanálise. Toma tais condutas como jogos simbólicos ou reais com a morte, nos quais o jovem coloca a si mesmo em jogo, com o objetivo de alterar suas capacidades simbólicas. Interroga-as como respostas à puberdade, em seu estatuto de sintoma e/ou de ato a partir de certas coordenadas da época atual.
\end{abstract}

Palavras-chave: Adolescência. Puberdade. Condutas de Risco

\section{INTRODUÇÃO}

O texto discute as condutas de risco praticadas por adolescentes e adultos jovens, na contemporaneidade, e as faz dialogar com conceito de puberdade em psicanálise.

O tema das condutas de risco foi debatido por autores franceses contemporâneos como Deburge, Duparc, Vasseur, Girard-Khayat, Robert, Le Breton e Lacadée. Este último, em seu livro O despertar e o exílio, faz uma análise da trajetória turbulenta do poeta francês, adolescente, Arthur Rimbaud.

Perguntamo-nos se tais condutas estão ligadas às dificuldades e impasses experimentados por estes sujeitos, ao posicionar-se no campo das identificações, particularmente no das identificações sexuais.

O campo clínico das condutas de risco é vasto. Inclui não apenas comportamentos em confronto direto com o mundo, mas, também, aqueles que ocorrem solitariamente e em silêncio. Entre eles estão o abuso de álcool, a toxicomania, as fugas, as errâncias, a condução de veículos em alta velocidade, os esportes radicais sem proteção adequada, a delinquência, as automutilações, e os sintomas alimentares.

Algumas condutas de risco são duradouras, permanecem certo tempo ou instauram um modo de vida. Outras são pontuais e transitórias. Envolvem determinações múltiplas, inclusive as inconscientes, e engajam significações variadas, que devem ser sempre pensadas no caso a caso.

Le Breton as definiu do modo que se segue: são jogos simbólicos ou reais com a morte, nos quais o jovem coloca a si mesmo em jogo, com o objetivo de alterar suas capacidades físicas e simbólicas (LE BRETON, 2007). Isto é, são condutas que envolvem o corpo, a vida e a morte, mas acima de tudo, estão

1 Doutora em Teoria Psicanalítica pela UFRJ. Psicóloga do Hospital das Clínicas da UFMG e Professora da Pontifícia Universidade Católica de Minas Gerais. 
ancoradas na linguagem. Primeiramente, porque respondem a uma insuficiência simbólica, que poderia assegurar a estes sujeitos um lugar no mundo, mas também porque são tentativas de reorganizar suas coordenadas simbólicas.

Costumam ter início na adolescência ou na primeira juventude adolescência estendida - momento em que as balizas da vida erótica, as do Eu, e de seus Ideais são retomadas com vistas à uma reordenação mais perene, posto que inaugura o ciclo da vida adulta.

\section{PUBERDADE, METAMORFOSE E ADOLESCÊNCIA}

A adolescência não é, propriamente, um conceito psicanalítico. O termo surge, no discurso, somente no início do século XX. Pode-se dizer, assim, que é relativamente recente a consideração da existência de um período particular da vida a ser isolado e diferenciado da infância e da idade adulta.

Freud usa pouco o termo adolescência (HERANWACHSEN). Utiliza, de preferência, a palavra puberdade (PUBERTÄT), quando indica a importância deste período para a reorganização das pulsões parciais da sexualidade infantil pregressa (FREUD, 1996b).

Dos três ensaios sobre a teoria da sexualidade, o terceiro é dedicado à metamorfose da puberdade, na qual Freud destaca duas mudanças fundamentais: a subordinação de todas as fontes de excitação sexual ao primado da zona genital e o processo de escolha objetal, ambas já prefiguradas na vida infantil e separadas pela latência.

A puberdade é apresentada como o momento de definição da vida sexual. Neste período, a escolha objetal é favorecida pelo incremento da pulsão sexual. A fantasia de realização do incesto torna-se mais premente e ameaçadora, exigindo seu recalcamento. Por fim, Freud diz que na puberdade, a pulsão sexual se coloca a serviço da reprodução. (FREUD, 1996b). Isto é, a pulsão sexual se imbrica com os laços e funções sociais. $O$ acasalamento, a maternidade e a paternidade surgem como situações possíveis.

Pode-se dizer, então, que a adolescência convoca o sujeito ao trabalho psíquico de restabelecer um circuito de gozo, circunscrito pela fantasia. Este trabalho sofre as incidências do Supereu e do Ideal do Eu, que estão em íntima relação com a construção de uma posição do sujeito, cujo desejo, laços, amorosos ou outros, passam a ser de outra natureza.

No "Projeto para uma psicologia científica", Freud atribui um papel relevante à puberdade na etiologia das neuroses, na medida em que as alterações ocorridas, neste momento, remontam à memória da sexualidade 
infantil e ao encontro traumático do sujeito com o sexual (FREUD, 1996a)

Neste sentido, é importante lembrar, que o processo vivido pelo púbere, abarca tanto as inscrições mnêmicas da sexualidade infantil, quanto aquilo que não se inscreveu desta sexualidade, no psiquismo. A saber, o real sexual, que não se traduziu em significantes e que insiste como exigência de satisfação pulsional silenciosa.

Alexander Stevens propõe que, na puberdade, as escolhas do sujeito são recolocadas tanto do lado da fantasia, que neste momento é posta à prova, quanto do lado do sintoma, que assume formas variadas. Para o autor, estas escolhas são recolocadas, mesmo se a estrutura psíquica já está decidida. E ele considera a adolescência como a idade de uma grande variedade de respostas possíveis ao surgimento do real próprio da puberdade (STEVENS, 2004).

Quando se trata de definir o real, ao qual o adolescente é convocado a se confrontar, encontramos diferentes indicações por parte dos autores, que giram em torno de temas muito semelhantes.

Para Melman (1999), o adolescente confronta-se com a perda de consistência dos ideais infantis, que o orientaram até então e, além disso, com a própria castração, em sua dimensão real, que está em jogo quando se trata da localização do gozo próprio.

Para Rassial (1999), o golpe de real sofrido pelo adolescente tem relação com as alterações anatômicas e fisiológicas do corpo, e com seu desamparo diante da insuficiência das referências simbólicas e imaginárias para lhe orientar em sua nova etapa de existência.

De acordo com Lesourd (2004), o real encontrado pelo sujeito, na puberdade, é a carne que irrompe no corpo, reintroduzindo um tipo de gozo que sua apreensão na linguagem afastara. Ele faz a distinção entre carne e corpo, efeito do recalcamento e do significante. Na puberdade, o retorno do real da carne tem o efeito de desarrimar o corpo tomado na linguagem, na medida em que abala a organização infantil. A adolescência é o trabalho subjetivo para circunscrever este real, por meio da re-inscricão do Nome do Pai no psiquismo ou pela invenção de novos Nomes do Pai (LESOURD, 2004).

O mesmo autor destaca ainda o feminino, na experiência vivida neste período. A puberdade marca o encontro com o feminino, que se divide entre a ligação com o falo e a descrença no mesmo, associada à ausência de significantes, que representem o gozo do sujeito. É o tempo de convocação à reconstrução dos véus fálicos sobre o feminino que se desnuda (LESOURD, 2004).

Lacadée diz que o adolescente se vê diante de um vazio, uma apresentação do real, relacionado às modificações que experimenta em seu corpo. Tomado pelo sentimento de estranheza, em função de sua metamorfose, o púbere se vê diante de algo intraduzível na língua do Outro, o que lhe dá a sensação de estar exilado do conjunto dos homens (LACADÉE, 2011). Sua tarefa, então, é 
encontrar nova língua para se dizer ao Outro, retomando uma posição no campo de significantes, veículo privilegiado das identificações. A tarefa do adolescente, pois, é a de fazer certa gestão do sexo, reconstruindo nova relação de gozo com o próprio corpo (LACADÉE, 2011).

Para Alexandre Steven, a inexistência da relação sexual é o que coloca a dificuldade de saber o que fazer quanto ao sexo. Trata-se, pois, da ausência de um saber constituído a priori sobre isso. No lugar da ausência da relação sexual, o sujeito deve elaborar um sintoma, uma resposta possível a este real impossível de circunscrever. A puberdade sendo um dos momentos em que, mais do que nunca, a não-relação sexual reaparece para o sujeito (Stevens, 2004).

Vê-se que as contribuições, citadas acima, não são antagônicas, pois se sobrepõem ou se complementam. Apontam para o arranjo particular que o púbere deve efetuar para a tomada de posição nos campos identitários, do desejo, e da sexuação.

Ocorre que, no contemporâneo, estes processos têm encontrado dificuldades e impasses, que os fazem turbulentos, instáveis, angustiosos e perturbadores. A metamorfose da puberdade tornou-se, hoje, mais intrincada e labiríntica do que nos tempos de outrora.

\section{A METAMORFOSE PÚBERE NA CONTEMPORANEIDADE}

Vários autores acentuam a faceta de crise da adolescência, na atualidade, que é fundamentalmente moderna, pois não a encontramos em textos antigos.

Lesourd afirma não ter encontrado vestígios do nosso adolescente moderno na história. E, embora o termo adolescência já apareça na antiguidade, seu sentido não é o mesmo da atualidade (LESOURD, 2004).

É com Rousseau, que a adolescência passa a ser vista como um momento de perturbação, provocado por paixões, e como o resultado da demanda social imposta ao sujeito para que ele estabeleça um caminho próprio, que definirá vários aspectos de sua vida.

Aparentemente, surgiu algo de novo no período histórico designado modernidade - ou pós-modernidade, como preferem alguns autores - que fez com que o conceito de adolescência tenha sido criado e associado à crise e, mais do que isso, tenha se tornado de uso psicológico.

Fala-se hoje, constantemente, da crise da adolescência e devemos nos perguntar o que este termo recobre. Alexandre Stevens o considera extremamente vago e até mesmo, "anticlínico", na medida em que vela as questões estruturais em jogo neste período (STEVENS, 2004).

O estabelecimento da adolescência como crise na modernidade, contudo, 
pode ser melhor compreendida, se entendemos que esta rompe com os tipos tradicionais de ordem social, introduzindo novas formas de relação do sujeito com o Outro, novas formas sintomáticas e novas formas de subjetivação.

As grandes guerras no século XX afetaram a ideia de que a humanidade se desenvolvia, apartando-se da barbárie e aproximando-se de ideais civilizatórios. A descrença no progresso, na possibilidade de confiança no outro fez com que a vida passasse a ser vista como uma experiência permanente de risco.

A experiência de desamparo do sujeito púbere no mundo pré-moderno, evidentemente, existiu, mas foi regulada de maneira muito mais eficaz, em função da duração e da consistência do sistema de regras. A sociedade moderna tornou-se fluida, e mais impermanente, o que levou Bauman a associá-la à liquidez (BAUMAN, 2007).

A modernidade é líquida porque nela tudo é móvel e este excesso de mobilidade, de demandas e de informações correspondem, no sujeito, à sensação de insuficiência e à banalização de suas experiências.

Além do mais, a oferta e o descarte ininterruptos de novos objetos, próprios do capitalismo, produzem como principal efeito a sensação de que o Eu é o que perde efetivamente valor (BAUMAN, 2007).

A desmontagem e efemeridade a que Bauman se refere, ao analisar a modernidade, incidem na construção de lugares possíveis para os sujeitos, no contorno insatisfatório do corpo, na fragilização dos laços sociais, e na frugalidade das relações amorosas.

O efeito de tudo isto, no campo da psicopatologia, é a constatação de que o rompimento com a segurança da tradição deu origem a uma modalidade de sujeito que, se por um lado, tem amplo acesso à singularidade e à autonomia, por outro, está continuamente atravessado pela angústia.

Verifica-se, também, o surgimento de uma série de novos sintomas relativos a perturbações de ordem narcísica e imaginária, posto que a época atual está marcada pelo narcisismo, pelo individualismo e pela alienação.

As relações especulares, que se sobrepõem às simbólicas, a presença onipresente do olhar através das câmeras, nas cidades ou na web, os reality shows, as redes sociais, fazem com que o olhar do Outro se confunda com o registro da própria existência.

O objeto olhar, estruturante no Estádio do Espelho, descrito por Lacan, passou a desempenhar, na modernidade, uma função proeminente na economia psíquica, fazendo com que os novos sintomas sejam marcados pela exterioridade, pelas perturbações narcísicas, e pela colocação em jogo do corpo próprio.

Adolescer tornou-se, portanto, um processo atravessado pelos elementos citados acima, os quais redefinem as estruturas subjetivas, sintomáticas, e as relações com o Outro.

Metamorfosear-se em uma época de incertezas, liquidez, e efemeridade, 
com coordenadas simbólicas e laços coletivos frágeis, tornou-se um percurso muito mais complexo do que foi no mundo da tradição, com seus ideais e lugares simbólicos bem circunscritos.

A adolescência acentuou, hoje, seus comportamentos de inquietação, instabilidade, angústia, impulsividade, desafio e transgressões.

Abandonar os ideais da infância, para adotar os da vida adulta, afirmar um veredito sobre sua vida futura e sobre sua identidade, assumir um lugar na partilha entre os sexos, definir algo a respeito do próprio desejo e gozo, em um mundo líquido, no qual o Outro perdeu consistência, tornou-se um empreendimento extremamente complexo.

Nota-se que o direito declarado ao gozo, o empuxo à satisfação das pulsões e às relações especulares fazem do corpo o cenário privilegiado para a manifestação das perturbações da puberdade.

O que buscamos mostrar é que a adolescência, como resposta ao real pubertário, hoje, é diferente daquela do mundo antigo. A clínica atual da adolescência introduz situações não vistas, anteriormente, com tanta frequência.

Cabe-nos perguntar se a adolescência nos dias atuais é de fato um sintoma, no sentido estrito do termo. E, em que medida, está, hoje, em diálogo com o Outro, e marcada pela castração.

A clínica nos traz, constantemente, casos de adolescentes, para os quais a questão do amor, do sexo, e do desejo, não estão bem colocadas

As situações abordadas nas condutas de risco recorrentes dos adolescentes, na atualidade, são exemplos de novos arranjos de resposta ao real da puberdade, que não se restringem a estrutura psicótica, mas são encontradas, muitas vezes, na estrutura neurótica. É importante, então, interrogar que função elas desempenham no processo vivido pelo adolescente.

\section{A FUNÇÃO DO RISCO NO PROCESSO DE METAMORFOSE NA PUBERDADE}

$\mathrm{O}$ risco, é certo, é algo inerente à existência humana. O ser humano teve sempre que lutar contra sua vulnerabilidade fundamental, as doenças, o cansaço, o acidente. Enfrentou sempre o fracasso, os lutos e a precariedade da continuidade da vida.

É no mínimo curioso, então, o fato de que no momento mesmo em que a sociedade chama por uma seguridade máxima, as pessoas façam do risco um desafio, uma revolta e um vício.

Le Breton faz notar que um aspecto geral, predominante na clínica das condutas de risco, é a ausência da orientação para existir e o sentimento de falta de borda, que fazem com que os jovens vivam uma relação fluida, e insegura 
com o mundo, experimentando ora a sensação de sufocamento, ora de vazio (LE BRETON, 2007).

De acordo com o autor, os jovens, apoiados em um sofrimento pessoal agudo ou difuso, parecem adotá-las como um último recurso para se colocar no mundo e acessar uma significação de si mesmos (LE BRETON, 2007).

Francois Duparc lembra que alguns antropólogos têm aproximado as condutas de risco contemporâneas aos ritos de iniciação das sociedades tradicionais, sobretudo à Ordália, uma confrontação com a morte através de um elemento natural (o fogo, o salto no vazio, o enforcamento, ou o combate), na qual a sobrevivência ou a morte assumem o valor do "julgamento de Deus" (DUPARC, 2006).

Nas sociedades tradicionais mencionadas, tais provas eram decididas pela coletividade, em função de um crime grave, misterioso, insensato ou indecidível, diante do qual nenhuma outra reparação era possível. A confrontação ao risco mortal permitia, assim, decidir se o individuo merecia ou não viver (DUPARC, 2006).

Aproximar a Ordália das condutas de risco atuais, nos permite perguntar se o desafio lançado à morte, por nossos jovens poderia ser uma espécie de apelo ao Outro ou a Deus (Outro fundamental). Não mais como na Ordália tradicional, conectada à ordem coletiva, mas de forma solitária, inconsistente e repetitiva.

Duparc agrupa algumas hipóteses dentro do campo da psicanálise que podem lançar luz sobre os mecanismos em jogo naqueles que repetidamente se colocam em risco: 1) A excitação ligada ao risco, promoveria uma espécie de descarga pulsional, substituta do amor e do ato sexual (este processo realizaria uma negação da diferença entre os sexos e da integração da sexualidade à adolescência). 2) As condutas de risco se aproximariam da estrutura da adição, determinando a repetição de atos que promovem a abolição da dimensão da fantasia, dos laços sociais e ligados, portanto, ao "mais além do princípio do prazer". 3) As condutas de risco traduziriam a carência narcísica daqueles que a praticam. Na falta de um terceiro edipiano bem integrado, eles buscariam consolidar o Eu insuficiente, e regular o gozo que os invade, através da colocação em jogo do corpo, da compulsão à repetição e do ato.

Os elementos, indicados por Duparc, podem lançar alguma luz sobre a pergunta que buscamos desdobrar neste texto, a saber, as relações entre as condutas de risco praticadas por jovens, na contemporaneidade e a puberdade, que exige a construção de uma identidade, sobretudo a identidade sexuada, acompanhada pela organização de certo modo de satisfação das pulsões.

As condutas de risco, de fato, promovem uma descarga pulsional e conferem certo tratamento ao gozo, mas não no campo do amor ou do desejo. Por isso, a adolescência, nestas situações, não nos parece ser, exatamente, um sintoma da puberdade (sintoma estruturado pela linguagem e que trata o real 
pelo simbólico). As condutas de risco aparecem justamente aí, onde o sujeito não consegue construir um sintoma.

Não temos, aqui, um trabalho psíquico elaborado, com vistas a tratar o real da puberdade. Temos, de preferência, atos, diferentes dos sintomas, pois não são organizados pela fantasia e não se oferecem à interpretação.

Nestes atos, não localizamos algo que possa ser reconhecido como a resposta do sujeito ao desejo enigmático do Outro, e, sim, uma convocação desesperada para que um Outro se constitua, e, portanto, o sujeito, que lhe é correlato.

Le Breton assinala, que é como se o jovem, não encontrando a certeza de seu lugar no mundo, buscasse esta certeza no corpo a corpo com o real. A intenção é a de buscar uma intensidade de ser, o corpo tornando-se o campo de batalha da identidade. (LE BRETON, 2009: p. 60).

As práticas de risco, cujo cenário é o corpo, nos indica um empobrecimento do simbólico, uma dissolução do sujeito e do Outro, no momento do ato.

Lacan indica, em $\mathrm{O}$ Seminário $\mathrm{X}, \mathrm{A}$ angústia, que o ato surge como o último tratamento da angústia, quando a inibição, a fantasia, e o sintoma falham (LACAN, 2004).

Tendo seus corpos invadidos por um gozo excessivo, os jovens, com seus atos arriscados, buscam tratar este excesso esboçando uma identidade e um corpo, com as marcas e cicatrizes aí inscritas. Talvez, por algum momento, alcancem uma espécie de apaziguamento, que é, contudo, transitório, e que os lança na repetição incessante de sua prática. $\mathrm{O}$ ato da conduta de risco é paradoxalmente a repetição da busca de tratamento deste excesso e de seu reiterado fracasso.

\section{REFERÊNCIAS}

BAUMAN, Z. Itentidade. Rio de Janeiro: Jorge Zahar Editor, 2004.

BAUMAN, Z. Le présent liquide. Rio de Janeiro: Jorge Zahar Editor, 2004.

DEBURGE, A. "Les conduites, à risque, autocalmants ou jouissance du calme". In: Les conduites à risque au regard de la psychanalyse. Paris: Éditions In Press, 2006.

DUPARC, F. "Les conduites à risque de la médiologie et de lánthropologie à la psychanalyse". In: Les conduites à risque au regard de la psychanalyse. Paris: Éditions In Press, 2006. 
DUPARC, F. "Láddiction au jeu". In: Les conduites à risque au regard de la psychanalyse. Paris: Éditions In Press, 2006.

FREUD, S. "Projeto para uma psicologia científica (1895)”. Em: Edição Standard das Obras Completas de Sigmund Freud. Rio de Janeiro: Imago, $1996 \mathrm{a}$.

FREUD, S. "Os três ensaios sobre a teoria da sexualidade (1905)". Edição Standard das Obras Completas de Sigmund Freud. Rio de Janeiro: Imago, 1996b.

GIRARD-KHAYAT, M. "Jouer avec le risque: une addiction?". In: Les conduites à risque au regard de la psychanalyse. Paris: Éditions In Press, 2006.

LACADÉE, P. O despertar e o exílio. Rio de Janeiro: Contra Capa, 20111.

LACAN, J. “Langoisse, Livre X, 1962-63”. Em: Le Seminaire, Paris: Éditions, du Seuil, 2004.

LE BRETON, D. Conduites à risque. Paris: PUF: 2007

LE BRETON, D. "Les conduites à risque et scarifications à ládolescence". In: Le corps dans le langage des adolescentes. Toulouse: Ères, 2009.

LESOURD, S. A construção adolescente no laço social. Rio de Janeiro: Vozes, 2004.

ROBERT, P. Une génealogie de línsecurité contemporaine. Entrevista com Philippe Robert. In: Esprit. Dez/2002, p. 35-58 


\title{
CONDUCT OF RISK AND PUBERTY
}

\begin{abstract}
The text discusses the risk behaviors practiced by adolescents in contemporary times and makes them dialogue with the concept of puberty in psychoanalysis. It takes such behaviors as symbolic or real games with death, in which the young man puts himself at stake in order to alter his symbolic capacities. It questions them as responses to puberty, in its status of symptom and / or act from certain coordinates of the present age.
\end{abstract}

Key Words: Adolescence. Puberty. Risk Practice

\section{CONDUCTA DE RIESGO Y PUBERTAD}

Resumén: El texto discute los comportamientos de riesgo practicados por los adolescentes en los tiempos contemporáneos y los hace dialogar con el concepto de pubertad en el psicoanálisis. Toma comportamientos tales como juegos simbólicos o reales con la muerte, en los que el joven se pone en juego para alterar sus capacidades simbólicas. Los cuestiona como respuestas a la pubertad, en su estado de síntoma y / o acto desde ciertas coordenadas de la era actual.

Palabras clave: Adolescencia. Pubertad. Conductas de Riesgo 